\title{
How we select articles for summary in the journal
}

\author{
Derek Richards \\ Editor, Evidence-based Dentistry
}

\author{
When this journal was launched the selection process for the journal focussed on \\ just $\mathbf{4 0}$ of the top dental journals, the Cochrane library and a selection of other \\ evidence-based journals. This process had now matured and this article describes \\ the current process. \\ Evidence-Based Dentistry (2004) 5, 50-51. doi:10.1038/sj.ebd.6400259
}

The first stage in the current selection process is a series of searches in Medline. These are conducted using the OVID [Ovid Technologies, New York, USA]. The first of the search strategies is based on the detailed strategy used by the Specialist library for Oral Health http:// libraries.nelh.nhs.uk/oralhealth/search_ filters.asp to identify dental papers (see Table 1).

The next stage is then the search for systematic reviews using a search strategy from the evidence-based project at McMaster University (Table 2). This can be seen on the specialist Oral Health Library at http://libraries.nelh. nhs.uk/oralhealth/search_filters.asp. This strategy is not one with maximum sensitivity i.e. it will not pick up every article which could be a systematic review but it is more precise. The results from the dental search and the systematic review search are them combined.
This whole process is repeated on Medline for randomised controlled trials (Table 3), and for prognosis, diagnosis and aetiology studies using search strategies which can be found on the Critical Skill Appraisal Programme (CASP) website www.phru.nhs.uk/casp/filters.htm

All the searches that are performed on Medline are limited to the last 3 years, currently from 2001 onwards. They are then limited to those conducted on humans. The searches are run at regular intervals, approximately every 3 months. All the identified papers are then downloaded to bibliographic management software so that duplicates can be readily excluded.

The titles and abstracts of these papers are then reviewed for clinical relevance. Copies of the relevant papers are then obtained and checked to see whether

Table 1. Search terms to identify dental papers on MEDLINE using OVID platform.

\begin{tabular}{|c|c|}
\hline Subject headings & Keywords \\
\hline $\begin{array}{l}\text { Anaesthesia, Dental/ } \\
\text { Comprehensive dental care/ } \\
\text { Dental anxiety/ } \\
\text { Dental Arch/ } \\
\text { Dental Caries/ } \\
\text { Dental practice management/ } \\
\text { Drill/ } \\
\text { exp Dental materials/ } \\
\text { exp Dental care/ } \\
\text { exp Dentistry/ } \\
\text { exp Dentition/ } \\
\text { exp Mouth Neoplasms/ } \\
\text { exp Periodontics/ } \\
\text { exp Preventive Dentistry/ } \\
\text { exp Radiography, dental/ } \\
\text { exp Tooth disease:/ } \\
\text { exp Dental Technology/ } \\
\text { exp Technology, Dental/ } \\
\text { Mouth Cancer/ } \\
\text { Oral health/ } \\
\text { Oral hygiene/ } \\
\text { Stomatology/ } \\
\text { Temporomandibular disorder:/ } \\
\text { Temporomandibular joint/ } \\
\text { Tooth/ }\end{array}$ & $\begin{array}{l}\text { Amalgam.mp. } \\
\text { Bruxism.mp. } \\
\text { Calculus.mp. } \\
\text { Caries.mp. } \\
\text { Cariology.mp. } \\
\text { Dental.mp. } \\
\text { Dentist:.mp. } \\
\text { Denture:.mp. } \\
\text { Enamel.mp. } \\
\text { Endonti:.mp. } \\
\text { Fluorid:.mp. } \\
\text { Gingiv:.mp. } \\
\text { Gum:.mp. } \\
\text { Mouth neoplasm:.mp. } \\
\text { Mouth rehabilitation.mp. } \\
\text { Occlusion.mp. } \\
\text { Odontometry.mp. } \\
\text { Oral.mp. } \\
\text { Orthodontics.mp. } \\
\text { Paedodont:.mp. } \\
\text { Periodont:.mp. } \\
\text { Plaque.mp. } \\
\text { Prosthodont:.mp. } \\
\text { Pulp.mp. } \\
\text { Tartar.mp. } \\
\text { Teeth.mp. } \\
\text { Temporomandibular.mp. } \\
\text { TMJ.mp. }\end{array}$ \\
\hline
\end{tabular}


Table 2. Systematic reviews search strategy.

\begin{tabular}{ll}
\hline 01 & meta-analysis.pt,sh. \\
02 & (meta-anal: or metaanal:).tw. \\
03 & (quantitativ: review: or quantitativ: overview:).tw. \\
04 & (systematic: review: or systematic: overview:).tw. \\
05 & (methodologic: review: or methodologic: overview:).tw. \\
06 & (integrative research review: or research integration:).tw. \\
07 & quantitativ: synthes:.tw. \\
08 & ( or 2 or 3 or 4 or 5 or 6 or 7 \\
09 & (medline or medlars).tw, sh. or embase.tw. \\
10 & (scisearch or psychinfo or psycinfo).tw. \\
11 & (psychlit or psyclit).tw. \\
12 & (hand search: or manual search:).tw. \\
13 & (electronic database: or bibliographic database:).tw. \\
14 & (pooling or pooled analys: or mantel haenszel).tw. \\
15 & (peto or der simonian or dersimonian or fixed effect:).tw. \\
16 & or/9-15 \\
17 & review.pt,sh. or review:.tw. or overview:.tw. \\
18 & 16 and 17 \\
19 & 9 or 18 \\
\hline
\end{tabular}

Table 3. Sensitive search strategy for Randomised controlled trials.

1. randomized controlled trial.pt.

2. dt.fs.

3. tu.fs.

4. random\$.tw.

5. or $/ 1-4$

they meet our criteria (see Criteria for Review and Selection for Abstracting page 52). Those papers that meet the criteria are then abstracted and sent for commentary prior to final inclusion in the journal.

In addition to searching Medline we also search the Cochrane Library on a quarterly basis and Embase six monthly. 